Idle Fictions 


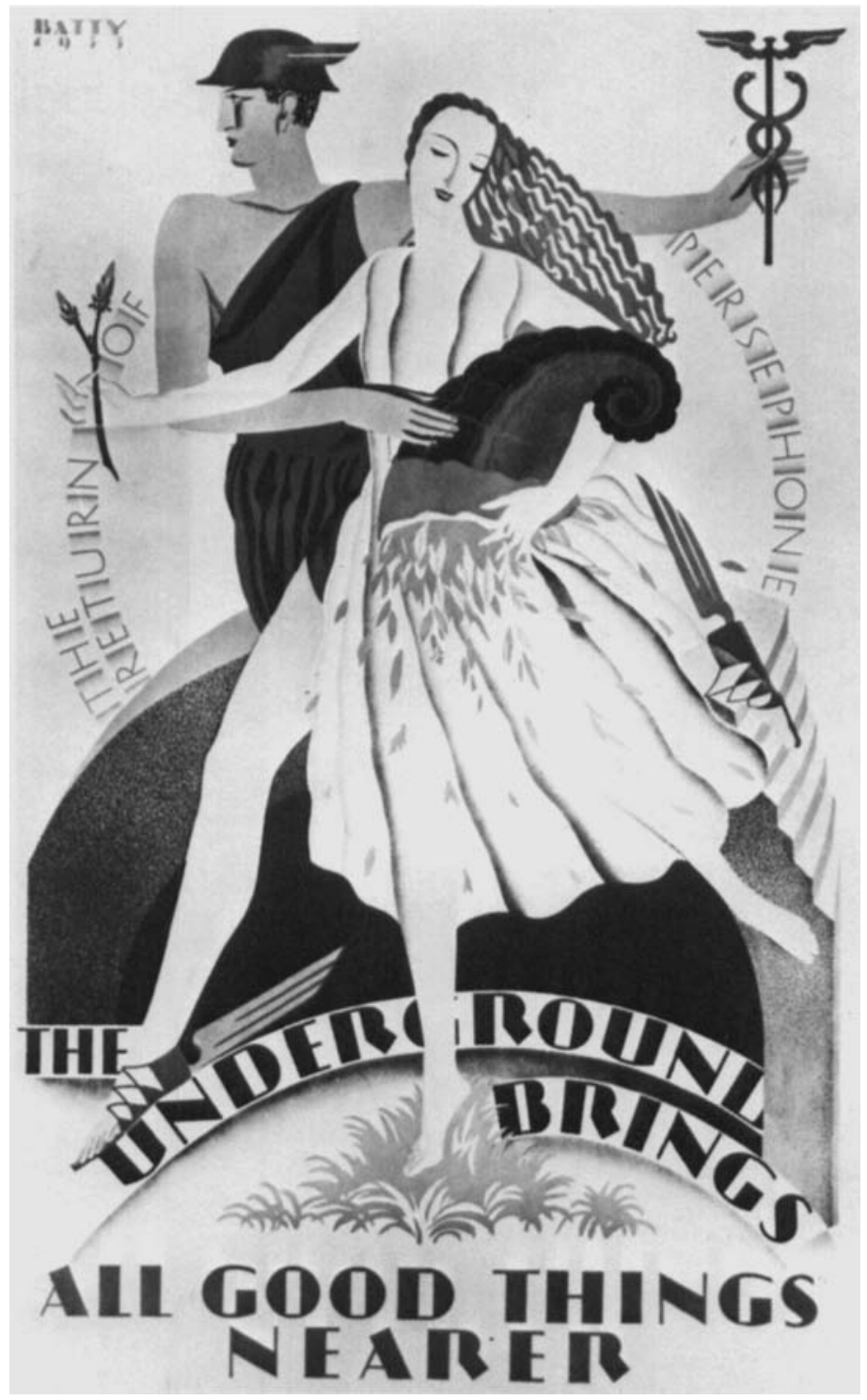




\section{Idle Fictions}

The Hispanic Vanguard Novel, 1926-1934

Gustavo Pérez Firmat 
This publication has been assisted by a grant from the Andrew W. Mellon Foundation.

(C) 1982, Duke University Press

First printing in paperback, 1993

All rights reserved

Printed in the United States of America on

acid-free paper $\infty$

Library of Congress Cataloging-in-Publication Data appear on the last printed page of this book.

Frontispiece:

Poster by Batty, "Return of Persephone"

(Reproduced by permission of the Victoria and Albert Museum: Crown copyright) 
A mis padres

There were several ways of understanding her: there was what she said, and there was what she meant, and there was something between the two, that was neither.

Henry James, The Europeans 
